\title{
Characterisation and radioimmunotherapy of LI9-SIP, an anti-angiogenic antibody against the extra domain B of fibronectin, in colorectal tumour models
}

\section{E El-Emir',', JLJ Dearling', A Huhalov', MP Robson', G Boxer', D Neri², GAMS van Dongen ${ }^{3}$, E Trachsel', RHJ Begent' and RB Pedley'}

'Cancer Research UK Targeting and Imaging Group, Department of Oncology, Royal Free and University College Medical School (UCL), Hampstead Campus, Rowland Hill Street, London NW3 2PF, UK; ${ }^{2}$ Institute of Pharmaceutical Sciences, Department of Chemistry and Applied Biosciences, Swiss Federal Institute of Technology Zurich, Wolfgang-Pauli-Str. 10, ETH Hoenggerberg, HCl G396, Zurich CH-8093, Switzerland; ${ }^{3}$ Department of Otolaryngology/Head and Neck Surgery, VU University Medical Centre, De Boelelaan III7, Amsterdam I08I HV, The Netherlands

\begin{abstract}
Angiogenesis is a characteristic feature of tumours and other disorders. The human monoclonal antibody LI9- SIP targets the extra domain B of fibronectin, a marker of angiogenesis expressed in a range of tumours. The aim of this study was to investigate whole body distribution, tumour localisation and the potential of radioimmunotherapy with the LI9-small immunoprotein (SIP) in colorectal tumours. Two colorectal tumour models with highly different morphologies, the SWI222 and LSI74T xenografts, were used in this study. Localisation and retention of the LI9-SIP antibody at tumour vessels was demonstrated using immunohistochemistry and Cy3labelled LI9-SIP. Whole body biodistribution studies in both tumour models were carried out with ${ }^{125}$ I-labelled LI9-SIP. Finally, ${ }^{131}$ I-labelled antibody was used to investigate the potential of radioimmunotherapy in SWI 222 tumours. Using immunohistochemistry, we confirmed extra domain B expression in the tumour vasculature. Immunofluorescence demonstrated localisation and retention of injected Cy3-labelled LI9-SIP at the abluminal side of tumour vessels. Biodistribution studies using a ${ }^{125}$ I-labelled antibody showed selective tumour uptake in both models. Higher recorded values for localisation were found in the SWI 222 tumours than in the LSI74T (7.9 vs 6.6\% $\mathrm{ID} \mathrm{g}^{-1}$ ), with comparable blood clearance for both models. Based on these results, a radioimmunotherapy study was performed in the SWI222 xenograft using ${ }^{131}$ I-Labelled LI9-SIP (55.5 MBq), which showed selective tumour uptake, tumour growth inhibition and improved survival. Radio- and fluorescence-labelled LI9-SIP showed selective localisation and retention at vessels of two colorectal xenografts. Furthermore, ${ }^{|3|} \mid$-LI9-SIP shows potential as a novel treatment of colorectal tumours, and provides the foundation to investigate combined therapies in the same tumour models.
\end{abstract}

British Journal of Cancer (2007) 96, I862-1870. doi:10.1038/sj.bjc.6603806 www.bjcancer.com

Published online 22 May 2007

(C) 2007 Cancer Research UK

Keywords: LI9-SIP; radioimmunotherapy; ED-B; vasculature; tumour

Radioimmunotherapy (RIT), the targeting of radiation to the tumour using monoclonal antibodies against tumour-associated antigens, has been used as a form of cancer treatment in both animal xenograft models as well as in humans (Pedley et al, 2001; Koppe et al, 2005). This form of therapy has the advantage of selectively targeting the tumour while reducing systemic toxicity. Solid tumours possess a heterogeneous pathophysiology and, therefore, the effectiveness of RIT depends on a range of factors including distribution of antibody uptake within the whole tumour mass and tumour vascularity.

Angiogenesis, the development of new blood vessels from preexisting vessels, is a common feature of solid tumours and other diseases such as blinding ocular disorders and rheumatoid arthritis. Angiogenic processes are regulated by a number of cell surface receptors and extracellular adhesion molecules (Ebbinghaus et al, 2004). The ability to selectively target

*Correspondence: Dr E El-Emir; E-mail: e.el-emir@ucl.ac.uk Revised 19 April 2007; accepted 24 April 2007; published online 22 May 2007 angiogenic molecules (markers) is useful for the delivery of therapeutic agents to the tumour. One potential marker for neovasculature is the extra domain B (ED-B) of fibronectin (FN).

Fibronectins are high-molecular-weight-adhesive glycoproteins abundantly expressed in vivo in the extracellular matrix and in body fluid (Kaspar et al, 2006). These play an important role in a number of biological phenomena such as maintenance of normal cell morphology, cell migration, haemostasis and thrombosis, wound healing, and oncogenic transformation (Castellani et al, 1994). Alternative splicing in the primary transcript results in multiple FN transcripts of the single copy gene. Three FN isoforms are expressed in tumour tissue and transformed cells, these include IIICS, extra domain A and ED-B (Ebbinghaus et al, 2004; Kaspar et al, 2006).

Extra domain-B domain is a complete type III repeat composed of a sequence of 91 amino acids, coded by a single exon and is the most conserved region of FN. It displays $100 \%$ homology in all mammalian species (Zardi et al, 1987). It is usually absent in both plasma and tissue FN of adults, except in regenerating tissues, such as some vessels in the endometrium. However, it is overexpressed 
during active tissue remodelling, for example, angiogenesis in tumours, wound healing and embryogenesis (Ebbinghaus et al, 2004; Kaspar et al, 2006). It has been shown to accumulate specifically around neovasculature in studies of many different tumour types, making it a good marker for angiogenesis (Carnemolla et al, 1989; Kaczmarek et al, 1994; Neri et al, 1997; Kosmehl et al, 1999; Tarli et al, 1999; Viti et al, 1999; Demartis et al, 2001; Castellani et al, 2002; Birchler et al, 2003; Ebbinghaus et al, 2004).

Human antibodies against the ED-B domain of FN, termed 'L19', have been isolated using different technologies (Pini et al, 1998; Borsi et al, 2002; Alessi et al, 2004). These include a complete human $\mathrm{IgG}$, dimeric $\mathrm{scFv}\left((\mathrm{scFv})_{2}\right)$ and a small immunoprotein (SIP). The L19-SIP is an $80 \mathrm{kDa}$ fragment composed of two scFv fused to the human $\epsilon_{\mathrm{s} 2}-\mathrm{CH} 4$ domain to provide a covalent stabilisation of the dimer (Li et al, 1997; Borsi et al, 2002).

Several fusion proteins based on the L19 antibody have been produced and characterised (Birchler et al, 1999; Nilsson et al, 2001; Halin et al, 2002; Halin et al, 2003; Ebbinghaus et al, 2005; Fabbrini et al, 2006). Furthermore, several radiolabelled derivatives of the L19 antibody have been studied in biodistribution experiments (Borsi et al, 2002) as well as being evaluated in clinical radioimmunscintigraphy studies (Santimaria et al, 2003). Biodistribution experiments and RIT studies with the L19-SIP antibody have been carried out in tumour-bearing mice and rats, and have demonstrated selective localisation in different tumour models, for example, human melanomas, mouse embryonal teratocarcinomas, human head and neck squamous cell carcinomas, and rat gliomas (Borsi et al, 2002; Berndorff et al, 2005; Spaeth et al, 2006; Tijink et al, 2006). Finally, the therapeutic potential of ${ }^{131}$ I-L19-SIP is currently being investigated in clinical trials in Italy and Switzerland (Kaspar et al, 2006).

In the present study, we have investigated for the first time, the distribution of the L19-SIP antibody in two human colorectal tumour models (SW1222 and LS174T), using both radio- and fluorescence-labelled antibody. We demonstrate that the radiolabelled antibody localises selectively in both tumour models. Furthermore, by employing high-resolution multi-fluorescence microscopy, we have been able to show that the antibody localisation is specific to the abluminal surface of the vessel. Finally, we show that RIT with ${ }^{131}$ I-L19-SIP causes tumour growth retardation and prolongs survival in preliminary therapy studies.

\section{MATERIALS AND METHODS}

\section{Antibody}

The L19-SIP (Mw $80 \mathrm{kDa}$ ), which targets the ED-B domain of FN consists of a fusion between two scFv and a $\mathrm{CH} 4$ domain of the human IgE, which mediates the homodimerisation of recombinant antibody (Borsi et al, 2002).

\section{Xenografts}

The human colorectal adenocarcinoma cell lines SW1222 and LS174T were used to develop subcutaneous xenograft models in the flanks of female nude mice (Pedley et al, 2001). SW1222 tumours are well differentiated and highly vascularised in comparison to the less differentiated and more poorly vascularised LS174T tumours (Pedley et al, 2002), and both represent morphologies frequently observed in the clinic.

Passaging was by subcutaneous implantation of small tumour pieces $\left(\sim 1 \mathrm{~mm}^{3}\right)$. Biodistribution experiments were carried out when tumours reached approximately $1 \mathrm{~cm}^{3}$. For therapy experiments, mice with palpable tumours of approximately $0.1 \mathrm{~cm}^{3}$ were used. All animal experiments were in compliance with the UK Coordinating Committee on Cancer Research (UKCCCR) guidelines for the Welfare of Animals in Experimental Neoplasia.
For immunohistochemistry and immunofluorescence staining, tumours were isolated, snap frozen in liquid nitrogen and stored at $-80 \mathrm{C}$.

\section{ED-B antigen expression}

Immunohistochemistry was performed on $10 \mu \mathrm{m}$ thick cryostat sections of both SW1222 and LS174T tumours after fixing in acetone for $10 \mathrm{~min}$ at room temperature. Following blocking of endogenous peroxidase with $0.3 \%$ of $\mathrm{H}_{2} \mathrm{O}_{2} /$ methanol for $15 \mathrm{~min}$ at room temperature, sections were first incubated in 3\% normal goat serum/phosphase-buffered saline (PBS) for $30 \mathrm{~min}$, followed by a1 h incubation with $2 \mu \mathrm{g} \mathrm{ml}^{-1}$ L19-SIP antibody at room temperature. After washing with PBS, the sections were then incubated with a horseradish peroxidase conjugated goat antihuman antibody (DAKO UK Ltd, Ely, UK) for $1 \mathrm{~h}$ at room temperature, rinsed in PBS, and then incubated with the avidinbiotin complex (Vector Laboratories Ltd, Orton Southgate, UK) following the manufacturer's instructions. Sections were developed with 3,3-diaminobenzidine (Sigma-Aldrich Company Ltd, Gillingham, UK) and counterstained with haematoxylin. Finally, sections were mounted in dibutyl phthalate xylene and visualised under a light microscope.

\section{Fluorescence-labelled antibody studies}

Fluorescence labelling The L19-SIP antibody was labelled with Cy3-NHS (Amersham Pharmacia, Little Chalfont, UK) according to the manufacturer's instructions. The final antibody to dye ratio was $1: 5$. A total of $100 \mu \mathrm{g}$ of labelled antibody was injected intravenously into the tail of the mouse $6 \mathrm{~h}$ before killing. Tumours were then excised, snap frozen in isopentane (cooled in liquid nitrogen), and stored at $-80^{\circ} \mathrm{C}$ until sectioned.

Tumour parameters To relate Cy3-L19-SIP antibody distribution to tumour morphology/pathophysiology, the following parameters were studied by multi-fluorescence microscopy:

(1) Perfusion: the in vivo DNA-binding dye Hoechst 33342 $\left(10 \mathrm{mg} \mathrm{kg}^{-1}\right)$ was injected intravenously $1 \mathrm{~min}$ before the mice were killed.

(2) Blood vessels: an anti-CD31 antibody was used to stain for blood vessel distribution, and the relevant immunohistochemical staining procedures were performed (see below).

(3) Nuclear staining: DAPI (4,6 diamidino-2-phenylindole) was used as a nuclear marker. This produces a blue fluorescence when bound to DNA.

Multi-fluorescence microscopy Sections $(10 \mu \mathrm{m})$ were first fixed in acetone for $10 \mathrm{~min}$ at room temperature, and then incubated with a 1:2 dilution of unconjugated anti-CD31 rat anti-mouse antibody (a kind gift from Professor A Mantovani) for $1 \mathrm{~h}$ at room temperature. After rinsing in PBS, sections were incubated with a 1:200 dilution of an Alexa Fluor 488 goat anti-rat antibody (Invitrogen Ltd, Paisley, UK) for $1 \mathrm{~h}$ at room temperature. After further rinsing with PBS, sections were mounted in either mounting medium containing DAPI (Vector Laboratories) or in PBS and viewed using an Axioskop 2 microscope (Carl Zeiss Ltd, Welwyn Garden City, UK), fitted with a computer-controlled motorised stage. Images were captured by an AxioCam digital colour camera using KS300 image analysis software (Zeiss, UK) (Pedley et al, 2002; El-Emir et al, 2005). Briefly, injected Hoechst 33342 and DAPI staining were visualised under a UV filter. Injected Cy3-L19-SIP and the CD31 signal were visualised under rhodamine and FITC filters, respectively. Both composite tiled images, consisting of a large number of individual fields, as well as high-resolution single images, for three different fluorophores 
(stained for three different parameters), were generated. Finally, the fluorescence images were then co-registered using Adobe Photoshop software, resulting in a new multi-channel image showing the inter-relationship between the overlapping fluorescently labelled structures.

\section{Radiolabelled antibody studies}

${ }^{125}$ I-labelling L19-SIP was labelled according to the IODO-GEN method as described by Visser et al (2001). Briefly, to an IODOGEN-coated glass tube, the following was added: $50 \mu \mathrm{l} 0.5 \mathrm{M}$ phosphate buffer, $\mathrm{pH} 7.4 ; 250 \mu \mathrm{g}$ L19-SIP $\left(0.5 \mathrm{mg} \mathrm{ml}^{-1}\right)$ in $0.1 \mathrm{M}$ phosphate buffer, $\mathrm{pH} 6.8 ; 50.18 \mathrm{MBq}{ }^{125} \mathrm{I}$ (Amersham Biosciences). The reaction was stopped after $4 \mathrm{~min}$ by the addition of $100 \mu \mathrm{l}$ of ascorbic acid $\left(25 \mathrm{mg} \mathrm{ml}^{-1}, \mathrm{pH}\right.$ 5). The solutions from two separate labellings were combined and purified on a PD-10 column and eluted with $0.9 \% \mathrm{NaCl} /$ ascorbic acid $\left(5 \mathrm{mg} \mathrm{ml}^{-1}, \mathrm{pH} 5.0\right)$. For the PD-10 column, the first $2.5 \mathrm{ml}(1 \mathrm{ml}$ sample volume and the first $1.5 \mathrm{ml}$ ) were discarded and the radiolabelled L19-SIP was collected in the next $2 \mathrm{ml}$.

${ }^{131}$ I-labelling Preparation of ${ }^{131}$ I-L19-SIP for therapy was performed according to the 'IODO-GEN-coated MAb method' (Visser et al, 2001; Tijink et al, 2006). Briefly, ${ }^{131} \mathrm{I}(444 \mathrm{MBq})$ was added to a glass vial in $1 \mathrm{ml} \mathrm{NaOH}\left(1 \mathrm{mmol}^{-1}\right)$, after which $10 \mu \mathrm{l}$ of ascorbic acid $\left(1.4 \mathrm{mg} \mathrm{ml}^{-1}\right)$ was added. After $5 \mathrm{~min}, 400 \mu \mathrm{l}$ of phosphate buffer $(0.5 \mathrm{M}, \mathrm{pH} 7.2)$ was added, followed by $3 \mathrm{ml}$ L19-SIP (approximately $1.5 \mathrm{mg}$ ) and $35 \mu \mathrm{l}$ IODO-GEN solution $\left(1 \mathrm{mg} \mathrm{ml}^{-1}\right.$ ). After $3 \mathrm{~min}$, the reaction was stopped by adding $100 \mu \mathrm{l}$ ascorbic acid $\left(25 \mathrm{mg} \mathrm{ml}^{-1}\right)$ followed after $5 \mathrm{~min}$ by the addition of $50 \mu \mathrm{l}$ human serum albumin (20\%). The solution was then purified on a $\mathrm{PD}-10$ column and eluted with $0.9 \% \mathrm{NaCl} /$ ascorbic acid $\left(5 \mathrm{mg} \mathrm{ml}^{-1}, \mathrm{pH} 5.0\right)$. The initial $2.7 \mathrm{ml}$ eluate $(2.2 \mathrm{ml}$ sample volume and the first $0.5 \mathrm{ml}$ ) was discarded and the radiolabelled L19-SIP was collected in the next $3.0 \mathrm{ml}$.

Analyses Thin layer chromatography (TLC) was used to assess radiopharmaceutical purity (silica gel $\mathrm{Si}_{60}$ stationary phase and citrate buffer (20 mM, pH 5.0) mobile phase).

The immunoreactivity of the radiolabelled protein was assessed on a $200 \mu \mathrm{l}$ volume ED-B sepharose column saturated with $0.25 \%$ BSA in PBS. An aliquot of radiolabelled antibody was applied to the column, which was then rinsed with $1.5 \mathrm{ml}$ of $0.25 \%$ BSA in PBS to remove non-specifically bound antibodies. Bound material was eluted using $1.5 \mathrm{ml}$ of $0.1 \mathrm{M} \mathrm{TEA}, \mathrm{pH} 11$. The radioactivity of the bound and unbound material was counted, using a $\gamma$-counter, and the immunoreactive percentage was calculated.

Biodistribution of ${ }^{125}$ I-L19-SIP Biodistribution experiments with the ${ }^{125}$ I-L19-SIP were carried out in both SW1222 and LS174T xenograft-bearing mice. Mice were injected in the tail vein with $8 \mu \mathrm{g}(0.26 \mathrm{MBq})$ of radiolabelled antibody and dissected at 1, 3, 6 or $24 \mathrm{~h}$ after injection. For each time point, four mice were killed and the following organs were excised, weighed and counted in a $\gamma$-counter (Cobra Multi Gamma Model 5010-Packard, UK): blood, tumour, liver, spleen, kidney, intestine, heart, lung, brain, muscle, stomach and tail. The radioactive content of the different organs was expressed as the percentage of injected dose per gram of tissue $\left(\% \mathrm{ID} \mathrm{g}^{-1}\right)$. Biodistribution experiments were analysed using Microsoft office Excel 2003.

Therapy Therapy experiments with ${ }^{131}$ I-L19-SIP were performed on SW1222 xenograft-bearing mice. To confirm that the ${ }^{131} \mathrm{I}$ labelled L19-SIP was selectively localizing to the tumour, and to compare localisation with ${ }^{125}$ I-labelled L19-SIP, a biodistribution study was first performed with the former. Each mouse was injected in the tail vein with $1.6 \mu \mathrm{g}(0.75 \mathrm{MBq})$ of radiolabelled antibody, and groups of four mice killed at 3,24 and $72 \mathrm{~h}$ after injection. Later time points (i.e., 24 and $72 \mathrm{~h}$ ) were included to investigate prolonged antibody retention, which is important for RIT efficacy. The following organs were excised, weighed and counted in a $\gamma$-counter: blood, tumour, liver, spleen, kidney, lung, colon, muscle, brain and stomach. The radioactive content of the different organs was expressed as $\% \mathrm{ID} \mathrm{g}^{-1}$.

For the RIT experiments, a group of four mice was injected, intraperitonially, with $117.5 \mu \mathrm{g}(55.5 \mathrm{MBq}){ }^{131} \mathrm{I}$-L19-SIP per mouse. A second group of six mice were used as untreated controls.

During treatment, tumours were measured twice weekly for a period of approximately 140 days, and tumour volume was estimated as the measurement of length $\times$ width $\times$ height $/ 2$ (Pedley et al, 2001). As well as observing general condition (e.g., respiratory distress, abnormal behaviour and no food/fluid intake), toxicity was assessed by using body weight measured every 3-4 days, as a surrogate marker. Mice were killed when tumours reached approximately $1.5 \mathrm{~cm}^{3}$ in volume. Therapy experiments were analysed using Microsoft office Excel 2003 and SPSS software. Survival was calculated using Kaplan-Meier analysis and showed significant correlation using the log-rank test $(P=0.0034)$. Suppression of tumour growth was analysed using a non-parametric test (Mann - Whitney $U$-test). This showed a significant difference in tumour size between untreated and therapy groups at day $13(P=0.038)$, which was sustained up until day $25(P=0.011)$.

\section{RESULTS}

\section{Antigen expression}

Before distribution studies with fluorescence-labelled L19-SIP, tumours were investigated for ED-B expression. Immunohistochemistry with the L19-SIP antibody confirmed that ED-B expression was associated with the majority of blood vessels as demonstrated in the SW1222 tumour model (Figure 1A). This was observed throughout the whole of the tumour.

\section{Distribution of fluorescence labelled L19-SIP}

Triple immunofluorescence staining of vessels (CD31), L19-SIP and perfusion (Hoechst 33342) over whole tumour sections, demonstrated that the antibody was associated with blood vessels in both peripheral and central regions of the tumour in the LS174T xenograft model (Figure 1B-D). However, co-registration of fluorescence staining for blood vessels, L19-SIP and cell nuclei (DAPI), revealed that not all CD31-stained vessels were L19positive (Figure 1E), indicating that ED-B was not associated with all tumour vessels. Furthermore, co-registration of fluorescence staining for CD31, L19-SIP and perfusion revealed that the L19-SIP had localised to the abluminal surface of the vessels, confirming that expression of EDB was in the extracellular matrix (i.e., stroma) of the tumour (Figure 1F).

\section{Radiolabelled L19-SIP}

As mentioned in the Materials and Methods section, L19-SIP antibody was labelled following the IODO-GEN method with both

${ }^{125} \mathrm{I}$ and ${ }^{131} \mathrm{I}$. Preliminary studies showed that the protein could be labelled using the methods described above and a plateau of labelling was found at $4 \mathrm{~min}$. Antigen binding of the labelled protein was found to be $91.7 \%$ for ${ }^{125}$ I-L19-SIP and $83.7 \%$ for ${ }^{131} \mathrm{I}$ L19-SIP. In addition, stability of the ${ }^{125}$ I-L19-SIP was assessed by TLC, and was found to be $99.2 \%$ after 5 days post-labelling.

\section{Biodistribution of ${ }^{125} \mathrm{I}$ - and ${ }^{131}$ I-labelled L19-SIP}

To compare localisation of the L19-SIP antibody in the two colorectal xenograft models, biodistribution studies were carried 

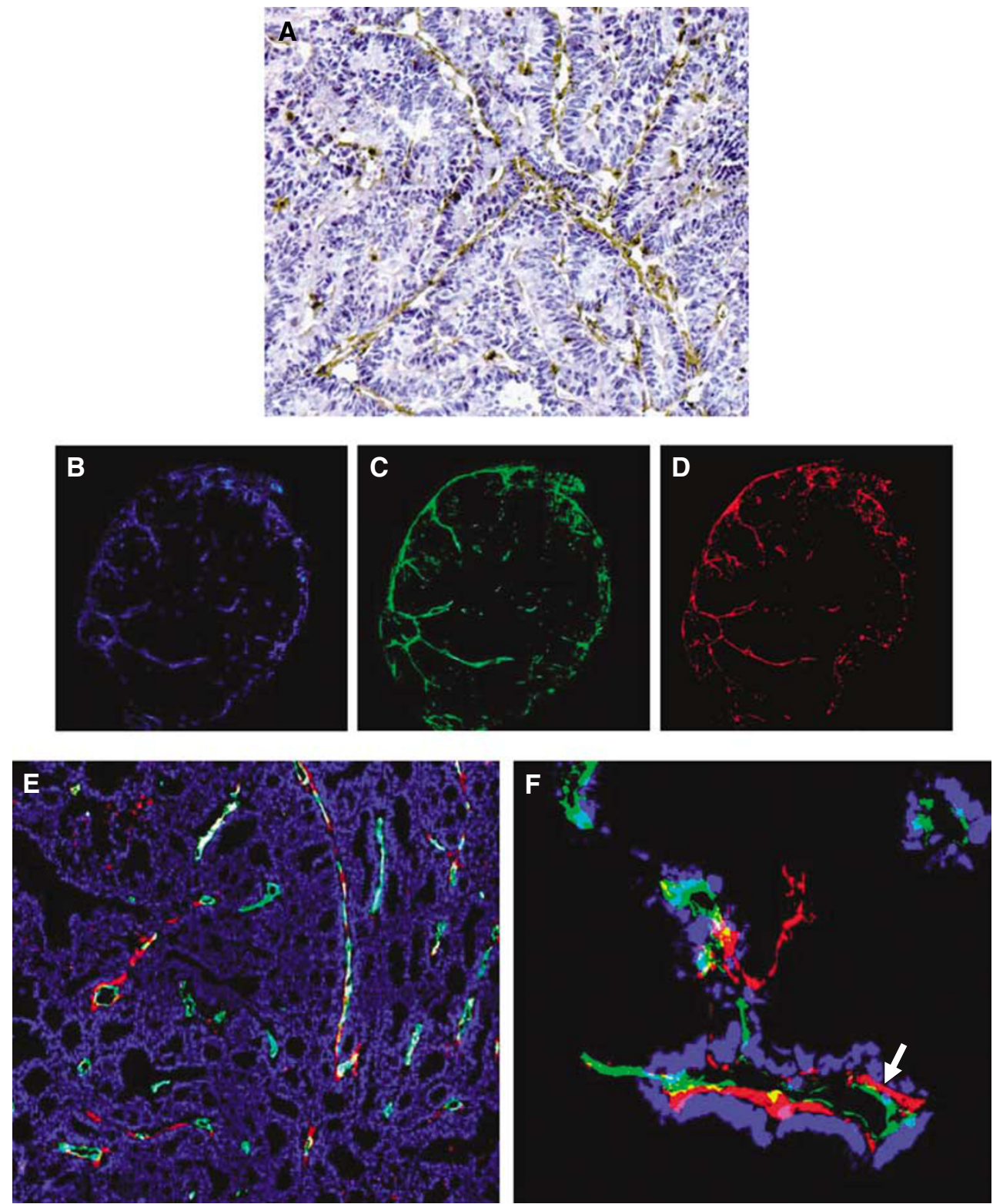

Figure I Immunohistochemical and immunofluorescence staining with LI9-SIP antibody in SWI222 and LSI74T xenograft-bearing mice. (A) Immunohistochemical staining of SW I 222 xenograft lines with LI9-SIP antibody. (B-D) Multiple digital fluorescence images of an LSI74T tumour injected with Cy3-labelled LI9-SIP antibody for $6 \mathrm{~h}$ demonstrating (B) perfusion, (C) blood vessel staining and (D) LI 9-SIP in the same tumour section. (E) Triple fluorescence staining of CD3I (green), LI9-SIP (red) and DAPI (blue) in LSI74T tumours. (F) High-power image of CD3I (green), LI9-SIP (red) and Hoechst (blue) staining in LSI74T (arrow indicating abluminal localisation of the LI9-SIP antibody). All images are at $\times 20$ magnification except (F) which is at $\times 40$ magnification.

out using ${ }^{125} \mathrm{I}$-labelled antibody (Figures 2 and 3). In SW1222 tumours, the $\% \mathrm{ID} \mathrm{g}^{-1}$ reached a maximum of $7.9( \pm 1.3)$ at $6 \mathrm{~h}$ after injection. In comparison, this reached a maximum of 6.6 $( \pm 4)$ at $3 \mathrm{~h}$ in the LS174T tumours. At $24 \mathrm{~h}$ post-injection, the $\% \mathrm{ID} \mathrm{g}^{-1}$ was $4.5( \pm 1.2)$ and $5( \pm 0.6)$ for SW1222 and LS174T, respectively.

Blood stability studies showed that at $1 \mathrm{~h} 86.45 \pm 1.39 \%$ of activity was associated with active protein (binding to antigen), reducing to $62.01 \pm 4.9 \%$ after $24 \mathrm{~h}$, in LS174T-bearing mice (Figure 4). This was confirmed after the bloods from the different time points had been run (Figure 4).

Tumour to blood ratios for the two tumour models are shown in Table 1. Initial blood clearance was faster in the SW1222 line than in the LS174T, but by $6 \mathrm{~h}$ post-injection, the blood clearance for both tumour models was comparable, with tumour to blood ratios of approximately 1.28 . However, at $24 \mathrm{~h}$, there was a higher tumour to blood ratio for the SW1222, which reached 4.22 in comparison to 3.37 for the LS174T. This led to a higher area under curve for the SW1222, measuring $151.6 \% \mathrm{ID} \mathrm{g}^{-1} \mathrm{~h}^{-1}$ vs 122.6 for the LS174T tumours.

On the basis of these results, the SW 1222 colorectal model was selected for a RIT study. A biodistribution study with the ${ }^{131} \mathrm{I}$ labelled L19-SIP was, therefore, carried out at 3, 24 and $72 \mathrm{~h}$ postinjection, to confirm the tumour specificity seen with ${ }^{125}$ I-labelled L19-SIP and to investigate long-term retention of antibody for RIT. Antibody distribution in tumour, blood and normal tissues is 


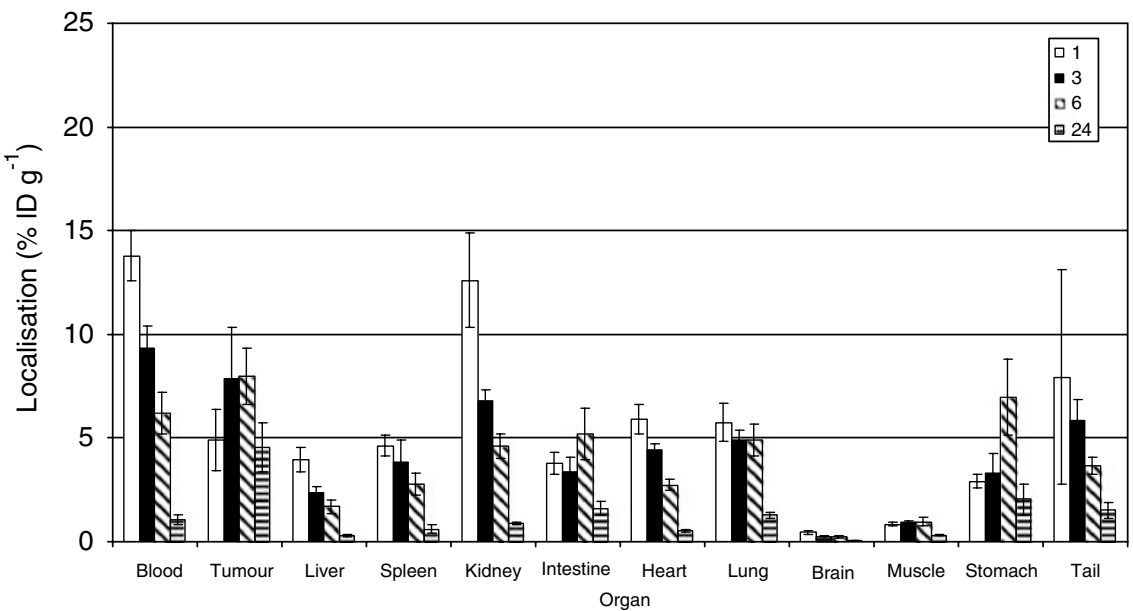

Figure 2 Biodistribution of intravenously injected ${ }^{125}$ I-LI9-SIP in SWI222 xenograft-bearing mice at I, 3, 6 and $24 \mathrm{~h}$ after injection. The mean \pm s.d. of four different mice are shown.

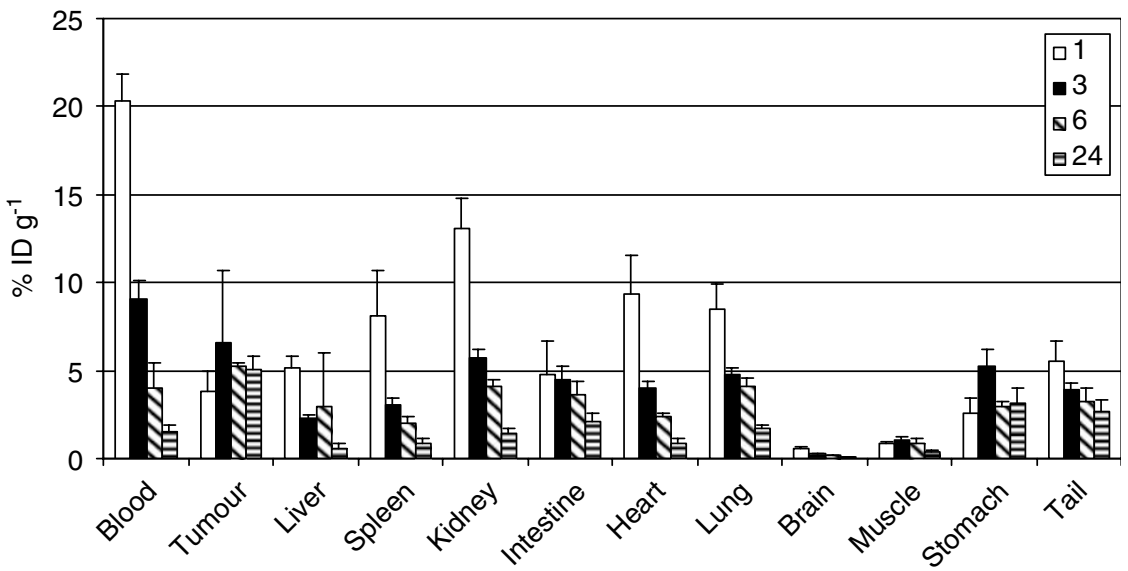

Figure 3 Biodistribution of intravenously injected ${ }^{125}$ I-LI9-SIP in LSI 74T xenograft-bearing mice at I, 3, 6 and $24 \mathrm{~h}$ after injection. The mean \pm s.d. of four different mice are shown.

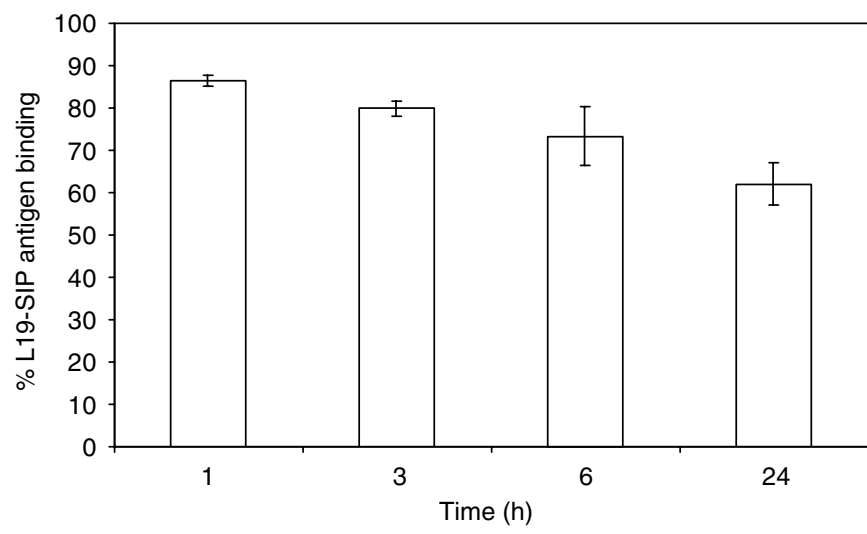

Figure 4 Blood stability data. Antigen binding of ${ }^{125}$ I-LI9-SIP in blood of LSI74T tumour-bearing mice at I, 3, 6 and $24 \mathrm{~h}$ post-injection. The mean \pm s.d. of four different mice are shown. Binding of the labelled protein before injection was $84.11 \%$.

shown in Figure 5. Uptake values in the tumour at 3 and $24 \mathrm{~h}$ were $5.4( \pm 3.6)$ and $8( \pm 5) \% \mathrm{ID} \mathrm{g}^{-1}$, respectively. By $72 \mathrm{~h}, 1.7$ $( \pm 0.8) \mathrm{HD} \mathrm{g}^{-1}$ was still retained in the tumour.
In addition, there was an increase in tumour to blood ratio of antibody over time, rising from 0.58 at $3 \mathrm{~h}$ to a maximum of 28 at $24 \mathrm{~h}$. Although this ratio decreased by $72 \mathrm{~h}$, it remained relatively high at 9.3 (Table 2).

\section{Radioimmunotherapy}

Radioimmunotherapy with ${ }^{131}$ I-L19-SIP produced a significant effect on tumour growth and survival in SW1222 xenograft-bearing mice. Treatment with a single dose of $55.5 \mathrm{MBq}$ mouse $^{-1}$ inhibited subsequent tumour growth for a mean of approximately 14 days (Figure 6) in comparison to control untreated mice, which showed a steady increase in tumour growth throughout the experiment. With the exception of one mouse, all tumours in the therapy group subsequently re-grew, although at a slower rate to that of controls. In addition to arrested tumour growth, RIT also resulted in a prolongation of survival (Figure 7). While all mice in the control group had been culled by day 32 , this was extended to 68 days for three of the treated mice. However, one out of four treated mice is apparently cured at 193 days post-injection.

Toxicity was assessed by regular weighing, and individual mouse weights are shown in Figure 8. In the treated group, mean body weight reached a nadir of $4 \%$ of the starting weight at day 4 post-therapy. Initial weight was regained at day 7, and subse- 
Table I Tumour to tissue ratios of ${ }^{125}$ I-L I9-SIP distribution in SWI 222 and LSI74T xenografts-bearing mice

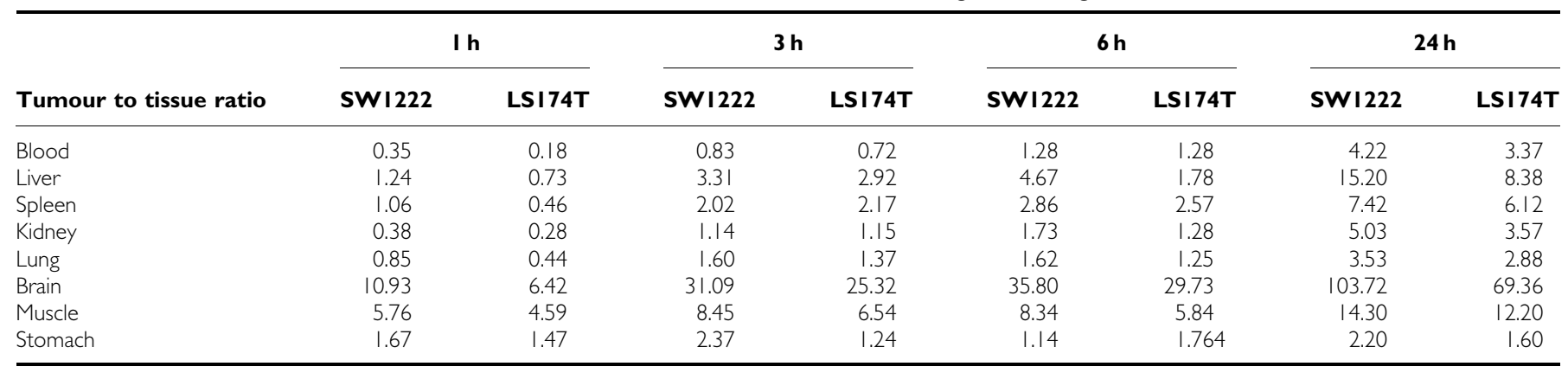

Table 2 Ratios of ${ }^{|3|}$ I-LI9-SIP distribution in SWI 222 xenograft-bearing mice

\begin{tabular}{lcrr}
\hline Ratio & $\mathbf{3 h}$ & $\mathbf{2 4 h}$ & $\mathbf{7 2 h}$ \\
\hline Blood & 0.58 & 28.11 & 9.36 \\
Liver & 2.01 & 24.10 & 33.21 \\
Spleen & 0.93 & 13.47 & 12.72 \\
Kidney & 1.14 & 7.82 & 7.62 \\
Lung & 1.07 & 6.95 & 7.62 \\
Brain & 9.71 & 69.99 & 135.68 \\
Muscle & 3.44 & 29.39 & 18.08 \\
Stomach & 2.15 & 4.56 & 3.60 \\
Colon & 4.61 & 4.62 & 3.44 \\
\hline
\end{tabular}

quently rose throughout the experiment. In comparison, control mice showed a mean weight loss of $1 \%$ at day 4 with a recovery exceeding initial values by day 7 .

\section{DISCUSSION}

In the present study, the distribution of the L19-SIP antibody in both SW1222 and LS174T colorectal tumour models has been investigated using both radio- and fluorescence-labelled antibodies. Furthermore, we have examined the potential of RIT against tumour vasculature in colorectal cancer, using ${ }^{131} \mathrm{I}$ in the SW1222 tumour model.

Using immunohistochemistry, the presence of ED-B was demonstrated around the vasculature in both tumour models (Figure 1A). This is supported by other studies in different tumour types (Zardi et al, 1987; Carnemolla et al, 1989; Castellani et al, 1994; Kaczmarek et al, 1994; Neri et al, 1997; D’Ovidio et al, 1998; Kosmehl et al, 1999; Tarli et al, 1999; Viti et al, 1999; Ebbinghaus et al, 2004).

We subsequently demonstrated, by multi-fluorescence microscopy, that fluorescence-labelled L19-SIP, when injected intravenously, localised specifically to tumour vessels at $6 \mathrm{~h}$ postinjection (Figure 1B-E). This distribution pattern was still retained at $24 \mathrm{~h}$ post-injection (data not shown). Fabbrini et al (2006) also demonstrated perivascular localisation of the L19-SIP in F9 teratocarcinoma-bearing mice. However, using high magnification, we could clearly show for the first time that the antibody is retained on the abluminal surface of the tumour blood vessels (Figure 1F).

We also found that not all vessels stained positive for L19-SIP (Figure $1 \mathrm{E}$ ), suggesting that ED-B expression may only be related to the neovasculature (i.e., immature newly formed vessels) of our two colorectal tumour models. To clarify this, we are currently using fluorescence microscopy and quantitative analysis to investigate whether a correlation pattern exists between EDB expression/L19-SIP localisation and blood vessel maturation in both SW1222 and LS174T tumour models. Specifically, we are looking at different vessel maturation markers, including those of the pericyte/mural cells as well as basement membrane markers, in different sized tumours. Preliminary data show that the majority of blood vessels within a tumour stain for both CD31 and L19-SIP regardless of tumour size, in comparison to control non-tumoural tissue which shows no L19-SIP staining around the blood vessels. These finding will be crucial when designing combined therapies with the L19-SIP antibody.

Having confirmed ED-B expression in the two colorectal xenografts, biodistribution experiments were performed. ${ }^{125} \mathrm{I}$ labelled L19-SIP antibody demonstrated good tumour uptake and localisation as early as $1 \mathrm{~h}$ post-injection in both models (Figures 2 and 3). However, we observed higher localisation of the L19-SIP antibody in the SW1222 tumours, which reached a maximum of $7.9 \% \mathrm{ID} \mathrm{g}^{-1}$ at $6 \mathrm{~h}$. In comparison, the $\mathrm{LS} 174 \mathrm{~T}$ tumours reached maximum of $6.6 \% \mathrm{ID} \mathrm{g}^{-1}$ at $3 \mathrm{~h}$ after injection. This difference in the L19-SIP antibody distribution may reflect the state of vascularisation within these tumours: the well-differentiated SW1222 tumours are highly vascularised in comparison to the less-differentiated LS174T tumours, which are poorly vascularised and therefore less accessible to the protein.

Blood clearance of ${ }^{125}$ I-L19-SIP antibody in both tumour models was comparable, with tumour to blood ratios of approximately 1.28 for both tumours at $6 \mathrm{~h}$ (Table 1). Borsi et al (2002), also demonstrated maximum localisation of the ${ }^{125}$ I-L19-SIP, $6.1 \% \mathrm{ID} \mathrm{g}^{-1}$, at $6 \mathrm{~h}$ in the SK-MEL-28 melanoma tumour-bearing mice, with tumour to blood ratios of 1.22 at this time point. More recently, using FaDu head and neck cancer xenograft-bearing mice, Tijink et al (2006), have also demonstrated maximum tumour localisation of ${ }^{125}$ I-L19-SIP antibody at $6 \mathrm{~h}$ post-injection.

When targeting antibodies to solid tumours, factors such as impaired microcirculation in newly formed vessels should be considered, as this may prevent antibody from rapidly reaching its target. Furthermore, the process of crossing the endothelial layer, which precedes the L19 antibody binding to the ED-B antigen on the abluminal surface of the vessel, could be retarded because of interstitial pressure. In addition, the endothelium itself has long been recognised as a natural barrier that may limit the uptake of antibodies in solid tumours. However, in the current study, we did not encounter these problems in our tumour models as both the ${ }^{125}$ I-L19-SIP and Cy3-labelled L19-SIP antibodies (data not shown) had clearly localised to their targets by $1 \mathrm{~h}$ after injection. Interestingly, we have observed blood vessel fenestrations in the SW1222 subcutaneous tumours using transmission electron microscopy (data not shown), which may play a role in the extravasation of the L19-SIP antibody and binding to its target, although the involvement of transcytosis cannot be ruled out. These findings, therefore, indicate few barriers to efficient localisation of the L19-SIP antibody in our tumour model; an 


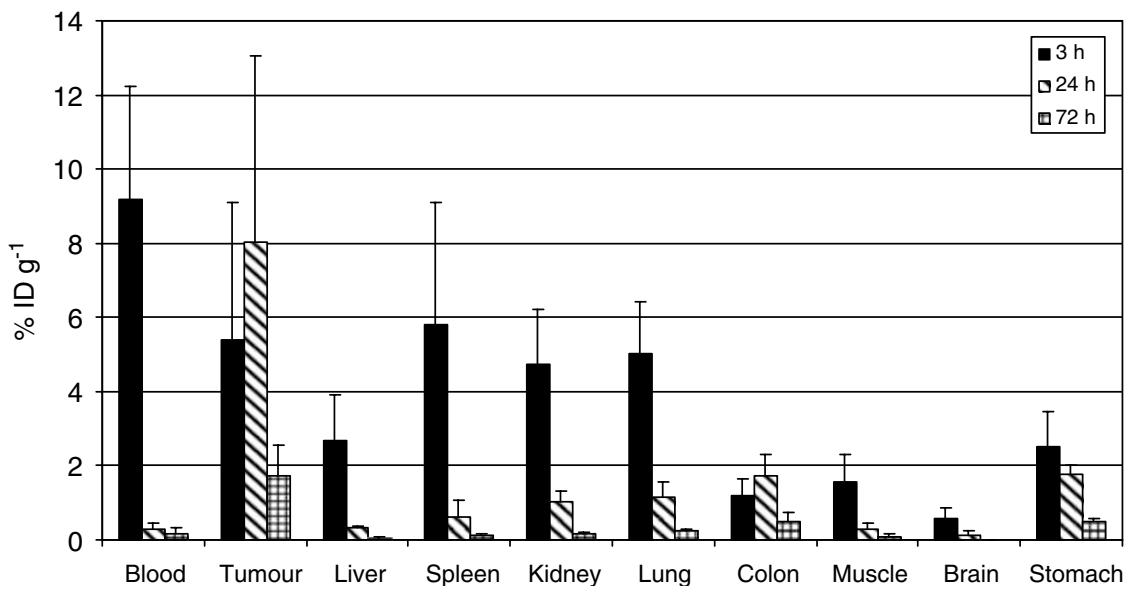

Figure 5 Biodistribution of intravenously injected ${ }^{131} \mathrm{I}-$ LI 9-SIP in SW I 222 xenograft-bearing mice at 3, 24 and $72 \mathrm{~h}$ after injection. The mean \pm s.d. of four different mice are shown.

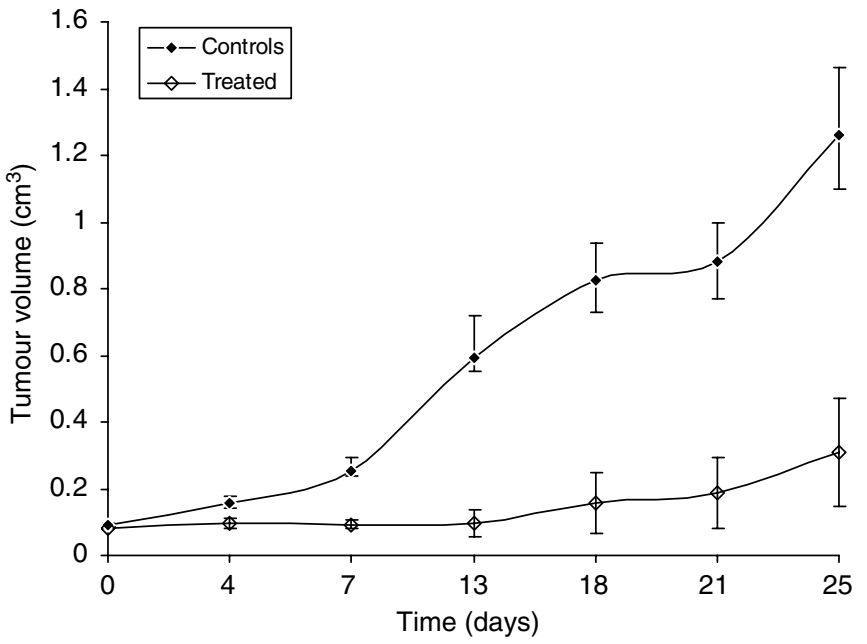

Figure 6 Tumour volumes of control and treated SWI222 xenografts following a single injection of $55.5 \mathrm{MBq}$ of ${ }^{131}$ I-LI9-SIP. The mean \pm s.e.m. of six mice for the control and four mice for the treated groups are shown.

essential point to be considered when planning timing of future combined therapy regimes.

In the current study, biodistribution experiments demonstrated higher recorded values for tumour localisation of the ${ }^{125}$ I-L19-SIP antibody in the SW1222 xenografts in comparison to LS174T tumours (Figures 2 and 3). Good accessibility and prolonged retention of the Cy3-L19-SIP antibody to its vessel-related target, which was observed as late as $24 \mathrm{~h}$ post-injection, was also shown in this tumour model. In view of this prolonged retention, and as ${ }^{131} \mathrm{I}$ has a range of emission of approximately $0.8 \mathrm{~mm}$ and the thickness of the tumour cord surrounding each tumour vessel in the SW1222 tumours is around $0.5 \mathrm{~mm}$, this isotope was considered the most suitable for RIT using this antibody. Therefore the therapeutic effect of the ${ }^{131}$ I-L19-SIP antibody was subsequently investigated in this model.

Biodistribution experiments, performed to confirm localisation of the therapeutic ${ }^{131}$ I-L19-SIP, showed maximum tumour localisation $\left(8 \% \mathrm{ID} \mathrm{g}^{-1}\right)$ at $24 \mathrm{~h}$ post-injection (Figure 5) in comparison to $6 \mathrm{~h}$ for ${ }^{125}$ I-L19-SIP (Figure 2). Interestingly, Tijink et al (2006) also demonstrated maximum localisation of ${ }^{131} \mathrm{I}$-L19SIP $\left(8.6 \% \mathrm{ID} \mathrm{g}^{-1}\right)$ in $\mathrm{FaDu}$ head and neck tumours at $24 \mathrm{~h}$.

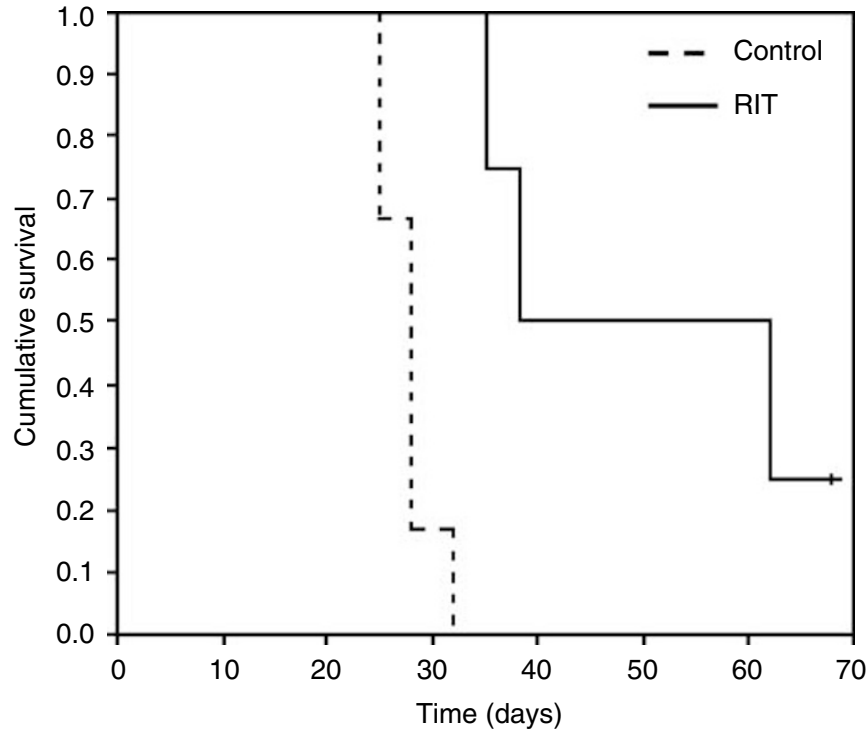

Figure 7 Survival of SW 1222 xenograft-bearing nude mice after a single injection of $55.5 \mathrm{MBq}$ of ${ }^{131}$ I-LI9-SIP.

Although higher radiolabelled antibody levels were found in blood at $3 \mathrm{~h}$ in the SW 1222 tumour model, this fell dramatically by 24 and $72 \mathrm{~h}$ post-injection, indicating good blood clearance and produced high tumour to normal tissue ratios. Indeed, at $24 \mathrm{~h}$, tumour to blood ratio was 28:1 (Table 2). This ratio was reduced at $72 \mathrm{~h}$, but still remained high at 9.4. In another study comparing the biodistribution of ${ }^{925}$ I-L19-SIP and ${ }^{111}$ In-L19-SIP in mice bearing the F9 teratocarcinoma tumours, Berndorff et al (2005) found that although tumour uptake was equal with both radionuclides, tumour to non-tumour ratios were higher for the ${ }^{125} \mathrm{I}$-labelled antibody.

RIT with ${ }^{131}$ I-L19-SIP caused significant tumour growth delay and improved survival in the SW1222 xenograft-bearing mice. A single dose of $55.5 \mathrm{MBq}$ of radiolabelled antibody significantly inhibited tumour growth for approximately 14 days (Figure 6).

After this time, the majority of the tumours recommenced growth; although one tumour currently appears cured (193 days post-treatment). However, as the group size of the treated mice was small, this finding must be considered as preliminary and would need to be further confirmed in a larger group of mice. 

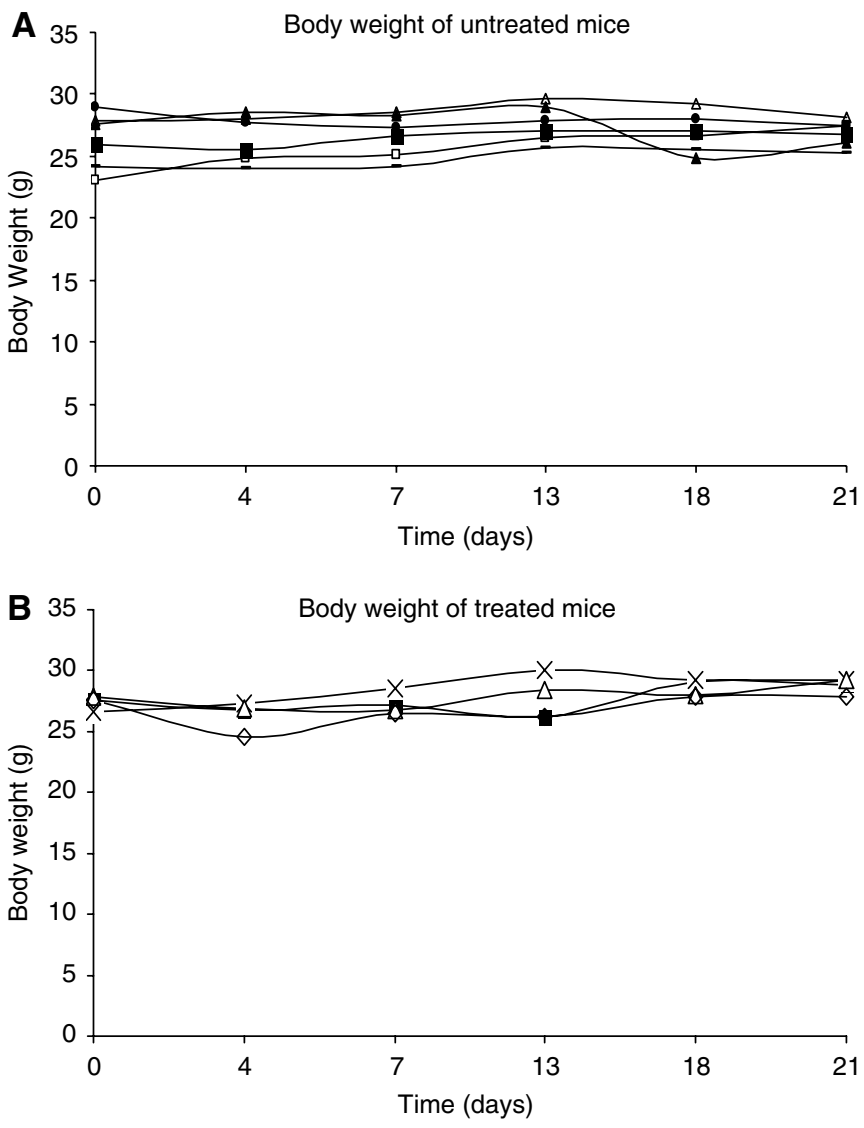

Figure 8 Individual body weights of $(\mathbf{A})$ control and $(\mathbf{B})$ treated mice bearing SW 1222 xenografts, after a single injection of $55.5 \mathrm{MBq}$ of ${ }^{131}$ I-LI 9 SIP.

We have shown previously that the blood vessels distribution in SW1222 tumours compose approximately $8 \%$ of total tumour mass (El-Emir et al, 2005). It is therefore encouraging that, although we are only targeting this relatively small percentage of the total tumour, the amount of localised radiolabelled antibody found by ourselves and other authors is sufficient to produce a significant therapeutic effect. Therefore, it can be considered very promising for clinical trials, and future work will involve demonstrating microscopically whether damage to both endothelium and tumour cells occurs following RIT with ${ }^{131}$ I-L19-SIP.

No significant weight loss was observed in the treated mice indicating that the relatively high doses of radiation used were not toxic. Interestingly, the rapid blood clearance leading to high tumour to blood ratios obtained at the later time points (24 and $72 \mathrm{~h}$ ) with ${ }^{131}$ I-L19-SIP may have contributed to the absence of toxicity. It is important to note that, in this study, significant results were obtained with doses lower than that used in other RIT studies with the L19-SIP antibody. Berndorff et al (2005) reported that a single injection of $74 \mathrm{MBq}^{131} \mathrm{I}$-L19-SIP to F9 tumour-bearing mice resulted in a 10-day tumour growth delay and a median survival of 22 days; 13 days longer than that of control mice. More recently, Tijink et al (2006) also demonstrated that a single dose of $74 \mathrm{MBq}{ }^{131}$ I-L19-SIP caused a maximum reduction in $\mathrm{FaDu}$ tumour size at day 18. However, at day 26, these tumours had re-grown to their initial size. The results reported in the current study, therefore, compare very favourably with these high-dose therapies, while using $25 \%$ less radioactivity (55.5 vs $74 \mathrm{MBq}$ ), and may be related to the high vascularity of the SW1222 tumours.

In contrast to RIT using antibodies against tumour cellassociated antigens which are expressed only in certain cancers, such as carcinoembryonic antigen in colorectal tumours (Pedley et al, 2001; Mayer et al, 2003), RIT with L19-SIP antibody, which selectively targets tumour vessels, has the advantage of being effective in a wide range of solid tumours (Berndorff et al, 2005; Spaeth et al, 2006; Tijink et al, 2006). Several options can now be explored to optimise the efficacy of RIT with ${ }^{131}$ I-L19-SIP, for example, repeated injection of the antibody. However, as the L19SIP is targeting the tumour vessels, which compose only a small percentage of the tumour mass, it is unlikely that the therapy will be totally effective as a single agent. Future experiments will, therefore, concentrate on selecting the optimal combined complementary therapies to overcome the problems of tumour heterogeneity and treat the entire tumour. These combined therapies are most effective when targeting different regions of the tumour. For example, it could be combined with other forms of RIT that target the tumour cells rather than the vasculature (Pedley et al, 2001). Tijink et al (2006) have shown that the combination of ${ }^{131}$ I-L19-SIP with Cetuximab, an anti-EGFR antibody, enhanced the efficacy of the RIT without causing an increase in toxicity.

In conclusion, this study demonstrates for the first time that ${ }^{125}$ I-L19-SIP and Cy3-L19-SIP showed good tumour selectivity in two human colorectal xenografts with highly different morphologies, and that RIT with ${ }^{131}$ I-L19-SIP caused a significant tumour growth delay and improved survival. This in turn, provides the basis for future combined therapies with RIT.

\section{ACKNOWLEDGEMENTS}

We thank Schering for kindly supplying the L19-SIP antibody and for their manuscript revision. We also thank Professor A Mantovani for kindly supplying the anti-CD31 antibody.

\section{REFERENCES}

Alessi P, Ebbinghaus C, Neri D (2004) Molecular targeting of angiogenesis. Biochim Biophys Acta 1654(1): 39-49

Berndorff D, Borkowski S, Sieger S, Rother A, Friebe M, Viti F, Hilger CS, Cyr JE, Dinkelborg LM (2005) Radioimmunotherapy of solid tumours by targeting extra domain B fibronectin: identification of the best-suited radioimmunoconjugate. Clin Cancer Res 11(19 Part 2): 7053s-7063s

Birchler M, Viti F, Zardi L, Spiess B, Neri D (1999) Selective targeting and photocoagulation of ocular angiogenesis mediated by a phage-derived human antibody fragment. Nat Biotechnol 17(10): 984-988

Birchler MT, Milisavlijevic D, Pfaltz M, Neri D, Odermatt B, Schmid S, Stoeckli SJ (2003) Expression of the extra domain B of fibronectin, a marker of angiogenesis, in head and neck tumours. Laryngoscope 113(7): 123

Borsi L, Balza E, Bestagno M, Castellani P, Carnemolla B, Biro A, Leprini A, Sepulveda J, Burrone O, Neri D, Zardi L (2002) Selective targeting of tumoural vasculature: comparison of different formats of an antibody (L19) to the ED-B domain of fibronectin. Int J Cancer 102(1): $75-85$

Carnemolla B, Balza E, Siri A, Zardi L, Nicotra MR, Bigotti A, Natali PG (1989) A tumour-associated fibronectin isoform generated by alternative splicing of messenger RNA precursors. J Cell Biol 108(3): $1139-1148$

Castellani P, Borsi L, Carnemolla B, Biro A, Dorcaratto A, Viale GL, Neri D, Zardi L (2002) Differentiation between high- and low-grade astrocytoma using a human recombinant antibody to the extra domain-B of fibronectin. Am J Pathol 161(5): 1695-1700 
Castellani P, Viale G, Dorcaratto A, Nicolo G, Kaczmarek J, Querze G, Zardi $\mathrm{L}$ (1994) The fibronectin isoform containing the ED-B oncofetal domain: a marker of angiogenesis. Int J Cancer 59(5): 612-618

Demartis S, Tarli L, Borsi L, Zardi L, Neri D (2001) Selective targeting of tumourneovasculature by a radiohalogenated human antibody fragment specific for the ED-B domain of fibronectin. Eur J Nucl Med 28(4): $534-$ 539

D’Ovidio MC, Mastracchio A, Marzullo A, Ciabatta M, Pini B, Uccini S, Zardi L, Ruco LP (1998) Intratumoural microvessel density and expression of ED-A/ED-B sequences of fibronectin in breast carcinoma. Eur J Cancer 34(7): $1081-1085$

Ebbinghaus C, Ronca R, Kaspar M, Grabulovski D, Berndt A, Kosmehl H, Zardi L, Neri D (2005) Engineered vascular-targeting antibody-interferon-gamma fusion protein for cancer therapy. Int J Cancer 116(2): $304-313$

Ebbinghaus C, Scheuermann J, Neri D, Elia G (2004) Diagnostic and therapeutic applications of recombinant antibodies: targeting the extradomain B of fibronectin, a marker of tumour angiogenesis. Curr Pharm Des 10(13): $1537-1549$

El-Emir E, Boxer GM, Petrie IA, Boden RW, Dearling JL, Begent RH, Pedley RB (2005) Tumour parameters affected by combretastatin A-4 phosphate therapy in a human colorectal xenograft model in nude mice. Eur $J$ Cancer 41(5): 799-806

Fabbrini M, Trachsel E, Soldani P, Bindi S, Alessi P, Bracci L, Kosmehl H, Zardi L, Neri D, Neri P (2006) Selective occlusion of tumour blood vessels by targeted delivery of an antibody-photosensitizer conjugate. Int J Cancer 118(7): 1805-1813

Halin C, Gafner V, Villani ME, Borsi L, Berndt A, Kosmehl H, Zardi L, Neri D (2003) Synergistic therapeutic effects of a tumour targeting antibody fragment, fused to interleukin 12 and to tumour necrosis factor alpha. Cancer Res 63(12): $3202-3210$

Halin C, Rondini S, Nilsson F, Berndt A, Kosmehl H, Zardi L, Neri D (2002) Enhancement of the antitumour activity of interleukin-12 by targeted delivery to neovasculature. Nat Biotechnol 20(3): 264-269

Kaczmarek J, Castellani P, Nicolo G, Spina B, Allemanni G, Zardi L (1994) Distribution of oncofetal fibronectin isoforms in normal, hyperplastic and neoplastic human breast tissues. Int J Cancer 59(1): 11-16

Kaspar M, Zardi L, Neri D (2006) Fibronectin as target for tumour therapy. Int J Cancer 118(6): $1331-1339$

Koppe MJ, Postema EJ, Aarts F, Oyen WJ, Bleichrodt RP, Boerman OC (2005) Antibody-guided radiation therapy of cancer. Cancer Metastasis Rev 24(4): 539-567. Review

Kosmehl H, Berndt A, Strassburger S, Borsi L, Rousselle P, Mandel U, Hyckel P, Zardi L, Katenkamp D (1999) Distribution of laminin and fibronectin isoforms in oral mucosa and oral squamous cell carcinoma. Br J Cancer 81(6): 1071 - 1079

Li E, Pedraza A, Bestagno M, Mancardi S, Sanchez R, Burrone O (1997) Mammalian cell expression of dimeric small immune proteins (SIP). Protein Eng 10(6): $731-736$
Mayer A, Tsiompanou E, Flynn AA, Pedley RB, Dearling J, Boden R, Begent RH (2003) Higher dose and dose-rate in smaller tumours result in improved tumour control. Cancer Invest 21(3): 382-388

Neri D, Carnemolla B, Nissim A, Leprini A, Querze G, Balza E, Pini A, Tarli L, Halin C, Neri P, Zardi L, Winter G (1997) Targeting by affinitymatured recombinant antibody fragments of an angiogenesis associated fibronectin isoform. Nat Biotechnol 15(12): 1271-1275

Nilsson F, Kosmehl H, Zardi L, Neri D (2001) Targeted delivery of tissue factor to the ED-B domain of fibronectin, a marker of angiogenesis, mediates the infarction of solid tumours in mice. Cancer Res 61(2): 711-716

Pedley RB, El-Emir E, Flynn AA, Boxer GM, Dearling J, Raleigh JA, Hill SA, Stuart S, Motha R, Begent RH (2002) Synergy between vascular targeting agents and antibody-directed therapy. Int J Radiat Oncol Biol Phys 54(5): $1524-1531$

Pedley RB, Hill SA, Boxer GM, Flynn AA, Boden R, Watson R, Dearling J, Chaplin DJ, Begent RH (2001) Eradication of colorectal xenografts by combined radioimmunotherapy and combretastatin a-4 3-O-phosphate. Cancer Res 61(12): 4716-4722

Pini A, Viti F, Santucci A, Carnemolla B, Zardi L, Neri P, Neri D (1998) Design and use of a phage display library. Human antibodies with subnanomolar affinity against a marker of angiogenesis eluted from a two-dimensional gel. J Biol Chem 273(34): 21769-21776

Santimaria M, Moscatelli G, Viale GL, Giovannoni L, Neri G, Viti F, Leprini A, Borsi L, Castellani P, Zardi L, Neri D, Riva P (2003) Immunoscintigraphic detection of the ED-B domain of fibronectin, a marker of angiogenesis in patients with cancer. Clin Cancer Res 9(2): 571-579

Spaeth N, Wyss MT, Pahnke J, Biollaz G, Trachsel E, Drandarov K, Treyer V, Weber B, Neri D, Buck A (2006) Radioimmunotherapy targeting the extra domain $\mathrm{B}$ of fibronectin in $\mathrm{C} 6$ rat gliomas: a preliminary study about the therapeutic efficacy of iodine-131-labeled SIP(L19). Nucl Med Biol 33(5): $661-666$

Tarli L, Balza E, Viti F, Borsi L, Castellani P, Berndorff D, Dinkelborg L, Neri D, Zardi L (1999) A high-affinity human antibody that targets tumoural blood vessels. Blood 94(1): 192-198

Tijink BM, Neri D, Leemans CR, Budde M, Dinkelborg LM, Stigter-van Walsum M, Zardi L, van Dongen GA (2006) Radioimmunotherapy of head and neck cancer xenografts using ${ }^{131}$ I-labeled antibody L19-SIP for selective targeting of tumour vasculature. J Nucl Med 47(7): 1127-1135

Visser GW, Klok RP, Gebbinck JW, ter Linden T, van Dongen GA, Molthoff CF (2001) Optimal quality (131)I-monoclonal antibodies on high-dose labeling in a large reaction volume and temporarily coating the antibody with IODO-GEN. J Nucl Med 42(3): 509-519

Viti F, Tarli L, Giovannoni L, Zardi L, Neri D (1999) Increased binding affinity and valence of recombinant antibody fragments lead to improved targeting of tumoural angiogenesis. Cancer Res 59(2): 347-352

Zardi L, Carnemolla B, Siri A, Petersen TE, Paolella G, Sebastio G, Baralle FE (1987) Transformed human cells produce a new fibronectin isoform by preferential alternative splicing of a previously unobserved exon. EMBO J 6(8): $2337-2342$ 